\title{
REPRESENTAÇÕES SOCIAIS DOS ENFERMEIROS SOBRE A TECNOLOGIA NO AMBIENTE DA TERAPIA INTENSIVA ${ }^{1}$
}

\author{
Rafael Celestino da Silva², Márcia de Assunção Ferreira ${ }^{3}$
}

\footnotetext{
${ }^{1}$ Recorte da dissertação “A tecnologia e o enfermeiro no ambiente da Terapia Intensiva: um encontro mediado pelas representações sociais", Programa de Pós-graduação em Enfermagem da Universidade Federal do Rio de Janeiro (UFRJ), 2008.

${ }^{2}$ Mestre em Enfermagem. Professor do Curso de Graduação em Enfermagem da Universidade Castelo Branco. Rio de Janeiro, Brasil. E-mail: rafaenfer@yahoo.com.br

${ }^{3}$ Doutora em Enfermagem. Professor Titular do Departamento de Enfermagem Fundamental da Escola de Enfermagem Anna Nery da UFRJ. Orientadora da dissertação. Rio de Janeiro, Brasil. E-mail: marciadeaf@ibest.com.br
}

\begin{abstract}
RESUMO: Objetiva-se identificar as representações sociais dos enfermeiros novatos e veteranos sobre a tecnologia própria aos ambientes de cuidados intensivos e analisar suas influências no cuidado ao cliente. Pesquisa qualitativa-descritiva com 24 enfermeiros de uma unidade cárdio-intensiva. Utilizou-se a Teoria das Representações Sociais, a entrevista semiestruturada e a análise temática de conteúdo. As representações sociais sobre a tecnologia se formam articuladas à gravidade e risco de morte do cliente, o que requer cuidados diferenciados e especiais. Por isso, o profissional deve ter características peculiares para atuar neste setor. Não há diferenças nas representações sociais de novatos e veteranos, mas a inexperiência dos novatos diferencia suas ações. Conclui-se que sejam necessárias estratégias que levem os enfermeiros a (re)interpretarem a tecnologia e políticas de alocação por especialidades e preferências dos enfermeiros pelos setores de atuação.
\end{abstract}

DESCRITORES: Tecnologia biomédica. Cuidados de enfermagem. Enfermagem. Unidades de terapia intensiva. Psicologia social.

\section{SOCIAL REPRESENTATIONS OF NURSES CONCERNING TECHNOLOGY IN THE INTENSIVE THERAPY ENVIRONMENT}

\begin{abstract}
The objective of this study is to identify the social representations of novice and veteran nurses concerning proper technology for intensive care environments and to analyze their influences on client care. It is a qualitative-descriptive study involving 24 cardio-intensive unit nurses. The Social Representations Theory, the semi-structured interview, and thematic content analysis were used. Social representations concerning technology are formed articulated to the gravity and risk of client death, which requires differentiated and special care. Therefore, the professional must have peculiar characteristics to perform in this sector. There are not differences in novice and veteran social representations, but the inexperience of novices differentiates their actions. One concludes that strategies that lead nurses to reinterpret the technology, as well as allocation policies for specialties and preferences of the nurses for the performance sectors are necessary.
\end{abstract}

DESCRIPTORS: Biomedical technology. Nursing care. Nursing. Intensive care units. Psychology, social.

\section{LAS REPRESENTACIONES SOCIALES DE LOS ENFERMEROS SOBRE LA TECNOLOGÍA EN EL AMBIENTE DE TERAPIA INTENSIVA}

RESUMEN: El objetivo del estudio es identificar las representaciones sociales de los enfermeros novatos y veteranos sobre la tecnología propia a los ambientes de cuidados intensivos y analizar sus influencias en el cuidado al cliente. Investigación cualitativa descriptiva con 24 enfermeros de una unidad de terapia intensiva cardiológica. Se utilizó la Teoría de las Representaciones Sociales, la entrevista semiestructurada y el análisis temático de contenido. Las representaciones sociales sobre la tecnología se forman articuladas a la gravedad y riesgo de muerte del cliente, por lo que se requiere cuidados diferenciados y especiales. Por ello, el profesional debe tener características peculiares para laborar en ese sector. No hay diferencias en las representaciones sociales de los novatos y los veteranos, pero la inexperiencia de los novatos diferencia sus acciones. Se concluye que son necesarias estrategias que lleven los enfermeros a (re) interpretar la tecnología, y políticas de asignación de los enfermeros por especialidades y preferencias por los sectores de actuación. DESCRIPTORES: Tecnología biomédica. Atención de enfermería. Enfermería. Unidades de terapia intensiva. Psicología social. 


\section{INTRODUÇÃO}

A problemática desta pesquisa se deu a partir de observações empíricas e assistemáticas sobre o fato de que trabalhar por longo tempo em determinado setor, não garante ao enfermeiro a sua permanência no mesmo. E, ainda, que critérios diferenciados orientam a alocação do pessoal de enfermagem nos setores hospitalares. Nesse sentido, o conhecimento e as experiências do profissional nem sempre são consideradas. Muitas vezes os profissionais trabalham em setores que não correspondem às suas preferências e qualificações. ${ }^{1}$

Além disso, os concursos públicos não levam em consideração as experiências profissionais, as especialidades dos enfermeiros, e nem mesmo suas expectativas. Nas unidades especializadas, principalmente nas de assistência intensiva e de alta complexidade, esta situação é mais preocupante. É comum encontrar nestes ambientes, equipes formadas por enfermeiros novatos ${ }^{2}$ que são alocados por necessidade dos setores e não por opção.

Novato é todo enfermeiro que entra em um campo de atuação no qual não tem experiência com a clientela, ou ainda não domina as ferramentas necessárias para o cuidado desta, mesmo que tenha experiência em outra área. Assim, novatos podem se responsabilizar pouco pelas situações, haja vista que essas situações são novas e estranhas.

Ao pensar nos cuidados de enfermagem realizados por este enfermeiro novato, frente ao impacto gerado pela alta tecnologia utilizada na assistência ao cliente que necessita de cuidados intensivos, é que vêm à tona as restrições e limitações de sua atuação. Isto porque, considera-se como de fundamental importância conhecer as particularidades da assistência prestada em Centros de Terapia Intensiva (CTI), uma vez que esta não se restringe à utilização de equipamentos e materiais e, além disso, tais clientes possuem necessidades diferentes dos clientes que se encontram internados em outras unidades hospitalares. Também é importante considerar que a maciça presença de equipamentos e processos tecnológicos exerce influência sobre todos que prestam cuidados neste ambiente. ${ }^{3}$

A problemática desta pesquisa perpassa pela atuação profissional do enfermeiro novato em cenários tecnológicos, uma vez que, pela sua condição, pressupõe-se que tais enfermeiros apresentem dificuldades para lidar com os recursos tecnológicos inerentes aos setores de assistência intensiva, instrumental, muitas vezes necessário para a identificação de necessidades dos clientes.
Muitos destes profissionais, ao entrarem em contato com este cliente portador de aparatos tecnológicos que lhe propicia a estabilidade hemodinâmica num momento crítico de recuperação, por não dominarem as tecnologias, mantêm-se afastados do cliente, ou manipulam-no pouco. Com isso, conjectura-se que o tempo de experiência no manejo da tecnologia incida na atuação profissional dos novatos, em comparação com as dos veteranos, os quais tendem a exibir uma prática mais segura.

A tecnologia, de modo geral, desperta nas pessoas curiosidade, fascínio e reservas. No campo da saúde, tais respostas são evidenciadas no cotidiano do trabalho, em especial no hospitalar e em cenários de Terapia Intensiva (TI) onde a curiosidade e o fascínio produzem aproximações a ela, e as reservas produzem afastamentos. Isto porque, a tecnologia na saúde, pelas repercussões que traz ao cuidado do cliente e ao trabalho do enfermeiro, em cenários nos quais ela se faz presente, produz saberes que levam a formação de sentidos sobre ela e influenciam as ações dos enfermeiros no cuidado. Este processo de elaboração sofre influência de experiências prévias, dos sistemas de referências e dos valores dos sujeitos, e implica na mobilização dos afetos que, em articulação, contribuem para formar representações sobre a realidade, no caso desta pesquisa, sobre o uso da tecnologia no cuidado.

Nesta perspectiva a tecnologia emerge como objeto psicossocial, pois os discursos que se produzem sobre ela trazem as marcas das experiências individuais dos sujeitos (dimensão psicológica), mas também das sociais construídas a partir das experiências e discursos coletivos que circulam nos grupos. Com este entendimento, as questões de pesquisa são - Quais são as diferenças entre as Representações Sociais (RSs) dos enfermeiros novatos e veteranos que atuam na terapia intensiva sobre a tecnologia própria a este setor? Que influências tais RSs trazem para as suas práticas de cuidado? Os objetivos são identificar as representações sociais dos enfermeiros novatos e veteranos sobre a tecnologia própria aos ambientes de cuidados intensivos, caracterizar suas diferenças e analisar suas influências no cuidado ao cliente.

As RSs sobre a tecnologia por enfermeiros que atuam em ambientes onde o avanço tecnológico é preponderante, nos dá subsídios para entender o modo como eles agem perante o cliente neste cenário. Esta pesquisa contribui para as discussões acerca do uso e incorporação da tecnologia e suas 
implicações para a prática de cuidar de clientes críticos em TI.

\section{METODOLOGIA}

Estudo descritivo, qualitativo, com aplicação da vertente processual da Teoria das Representações Sociais (TRS). Esta teoria aplica-se aos estudos sobre o universo de conhecimento do senso comum, e investe em desvelar os saberes práticos que orientam os sujeitos no mundo. ${ }^{4}$ Os objetos de pesquisa em RSs são psicossociológicos, guardando relações entre o universo subjetivo e social dos sujeitos, pela importância que adquirem em seus cotidianos de vida. Nesse sentido, a tecnologia nesta pesquisa é entendida como objeto passível de RS, uma vez que tem relevância para o grupo de enfermeiros, em especial para aqueles que atuam em CTI. À luz desta teoria, na formação das RSs, os sujeitos processam as informações advindas do universo científico com as que circulam nas conversações cotidianas e com os saberes de suas próprias experiências sensíveis. Re-elaboram o conhecimento que o ajuda a orientar suas ações. ${ }^{4}$

O cenário foi a Unidade Cardio-Intensiva de um hospital federal de grande porte localizado no município do Rio de Janeiro. Do total de 30 enfermeiros deste setor, 24 aceitaram participar do estudo. Foram excluídos os que se encontravam afastados do trabalho por qualquer motivo e os que não concordaram em participar. Em virtude da problemática da pesquisa e por considerar que o tempo de atuação profissional possa exercer influência significativa nas RSs sobre a tecnologia, os enfermeiros foram classificados segundo o tempo de atuação: novatos - aqueles com atuação profissional de até dois anos em setores altamente tecnológicos, num total de 11; e veteranos - aqueles com atuação profissional superior a dois anos em tais setores, num total de 13 .

Os dados foram coletados no período de outubro de 2007 a março de 2008. Realizou-se entrevista individual, com aplicação de um roteiro semiestruturado. Ao conteúdo das entrevistas foram aplicadas as técnicas de análise temática de conteúdo. ${ }^{5}$ As categorias empíricas foram construídas ao final da operação de análise em torno de quatro temas que aludem ao ambiente, ao cliente, ao cuidado e ao profissional do CTI.

$\mathrm{O}$ anonimato dos sujeitos foi garantido através de código alfa-numérico cujo significado é o seguinte: $\mathrm{E}$ (enfermeiro), $\mathrm{N}$ (novato), $\mathrm{V}$ (veterano), $\mathrm{F}$ (sexo feminino), $\mathrm{M}$ (sexo masculino), $\mathrm{N}$ (turno noturno), D (turno diurno), seguido do número corresponde à ordem sequencial das entrevistas.

O projeto foi aprovado pelo Comitê de Ética em Pesquisa do Hospital dos Servidores do Estado$\mathrm{RJ}$, protocolo $\mathrm{N}^{\mathrm{o}} 298$. Todos os sujeitos assinaram o Termo de Consentimento Livre e Esclarecido em atendimento às exigências constantes na Resolução No 196/96 do Conselho Nacional de Saúde.

\section{RESULTADOS E DISCUSSÃO}

\section{A díade ambiente-cliente}

Para falar da tecnologia e fazer emergir suas representações, foi solicitado aos sujeitos que falassem sobre o ambiente do CTI. Constatou-se que este ambiente é marcado por significados e simbolismos que são estabelecidos em resposta à presença da tecnologia neste local. Uma das concepções que distingue esse ambiente como peculiar é a sua ligação com o sofrimento e a morte iminente. Parte-se de uma compreensão de que estar sob cuidados em um setor rodeado por recursos tecnológicos remete a uma associação com maior sofrimento e proximidade com a morte, onde a idéia de finitude ganha contornos mais definidos. As unidades tecnológicas se caracterizam pela morte, sendo consideradas como o último local pelo qual o cliente passa antes de morrer.

A maioria das pessoas pensa que é um lugar onde as pessoas vão morrer, pelo menos no que eu vejo, no imaginário popular, até o meu mesmo antes de entrar para área da saúde, se você tem um parente, e você sabe que a pessoa foi entubada, que a pessoa está precisando de um respirador, está precisando de um monitor, a primeira coisa que você pensa é que a pessoa não vai sair, que a pessoa vai morrer, que a pessoa não vai ficar bem (ENFD1).

Os familiares, eles sempre pensam que a unidade coronariana é um lugar assim, que a pessoa está muito mal, ou então, principalmente o pós-operatório-imediato, a pessoa vem entubada, vem com os drenos, então acha que a pessoa está muito grave, que vai morrer, só porque está no CTI [...] eu acho que a grande maioria pensa que é um setor para quem está nas últimas (EVFD6).

O ambiente é ainda caracterizado pelos enfermeiros como um local que assusta, provoca medo nas pessoas, principalmente quando se fala nos clientes. Tal medo é justificado pela existência de vários caracteres que lhes são desconhecidos, aos quais também vinculam a idéia de gravidade, ou seja, quanto mais aparato tecnológico estiver se utilizando mais grave se está. Os aparatos 
tecnológicos se constituem em um desconhecido que, articulado com a noção de gravidade, desencadeiam o medo.

Acho que eles [pacientes] também têm medo. Ele [paciente] sai do seu ambiente de segurança, vai para um ambiente completamente novo para ele e não sabe metade do que é aquilo que está à volta dele. Não sabe a diferença entre o fio que está no peito e o que está no dedo. Então, ele [paciente] vai ter medo sim, ele fica apavorado (EVFN16).

Eu acho que uns ficam assustados. Com muitos aparelhos, acho que às vezes vinculam a gravidade do quadro dele com o uso de muita tecnologia. Pensam que quanto mais tecnologia está sendo usada, mais grave eles estão. Então eu acho que isso assusta um pouco o paciente de uma forma geral (ENFN14).

O ambiente tecnológico do CTI apresenta-se como um ambiente desconhecido e estigmatizado para clientes e familiares. A falta de informação e de um conhecimento prévio acerca dos elementos que permeiam o cuidado neste cenário geram insegurança e medo, e fazem com que o CTI seja considerado no âmbito do senso comum, como o último lugar do hospital na hora da morte. Desta forma, a hospitalização no CTI é algo que desperta o medo da morte, isto é, quando um cliente entra neste centro é porque está entre a vida e a morte. Assim, percebe-se que existe um estigma na palavra CTI, e na qual a questão da morte está imbricada na noção pré-concebida acerca da internação neste setor. O medo de morrer vem à tona principalmente quando os clientes vivenciam a situação de morte de outros clientes internados no mesmo setor. ${ }^{6}$

Uma pesquisa que objetivou conhecer as contradições que se revelam na prestação do cuidado humanizado do enfermeiro no CTI, mostrou que pelo fato deste setor ser um ambiente especial, em que a gravidade, as intervenções invasivas e o risco da morte sejam frequentes, cria-se um imaginário da morte, dor e sofrimento. O senso comum que perpassa o imaginário social dos acompanhantes é marcado por um sentimento de pesar pela proximidade da morte, com a visão negativa criada pela quantidade de aparatos tecnológicos responsáveis pela manutenção da vida do cliente na unidade. ${ }^{7}$

Com base no exposto, evidencia-se que ao serem internados no CTI, os clientes e seus familiares vivenciam sentimentos peculiares que são produzidos a partir das idéias que circulam na sociedade acerca deste ambiente, e das suas características físicas e funcionais, que, na verda- de, se apresentam como desconhecidas para eles. Afirma-se, portanto, que existe uma pré-concepção sobre o ambiente do CTI que o aproxima da morte. Tal concepção está intimamente relacionada ao fato de que neste ambiente há muitos aparatos tecnológicos que representam a gravidade do cliente, isto é, quanto mais aparato, mais grave o cliente está, e quanto mais grave, mais próximo da morte se encontra. Assim, a tecnologia no CTI pressupõe um estado para o cliente.

Considera-se que exista uma representação social sobre o ambiente de terapia intensiva que o vincula a uma noção de terminalidade, finitude, sofrimento e gravidade. Esta representação orienta o modo como os enfermeiros estruturam o pensamento sobre a tecnologia, ou seja, as idéias pré-concebidas sobre o ambiente do CTI, formadas com base na circulação de informações, seja nas rodas de conversa ou a partir do acesso aos meios de comunicação em massa, fazem com que o enfermeiro, ao entrar em contato com este cenário marcado por aparatos tecnológicos extremamente avançados, articule tal imaginário ao uso da tecnologia no cliente.

O uso das tecnologias avançadas no cliente, pelo fato de exercerem poder sobre a vida, denota um retrato de gravidade e provável morte. Por sua vez, tal representação construída sobre ela fortalece ainda mais o sentido que é atribuído ao ambiente, de modo que ambas passam a estar implicadas, retroalimentando-se mutuamente.

A tecnologia acoplada ao cliente faz pressupor seu estado, funcionando como um agente caracterizador de alguns elementos que compõem o cuidado que se processa em ambientes tecnológicos.

Uma das funcionalidades das RSs é denominar e classificar os objetos para lhes dar sentido, ajudando os sujeitos a melhor lidar com eles. ${ }^{4}$ Assim, se observa que à luz das RSs dos enfermeiros, a tecnologia os ajuda a tipificar o cliente que necessita de tecnologia e a tipificar elementos do cuidado. Deste modo, os enfermeiros distinguem este cliente de uma maneira em que a tecnologia institui um quadro clínico associado à idéia de gravidade, instabilidade e complexidade. Logo, estar num ambiente sob uso de determinadas tecnologias denota estar mais grave, sob maior risco de vida do que aqueles que não as utilizam. Além disso, este cliente tem maior propensão a desenvolver intercorrências ou agravar o quadro clínico, o que justifica a aproximação com a instabilidade. Para cuidar deste cliente é necessário 
reunir vários saberes, bem como lançar mão de uma série de instrumentos do cuidado. Por isso, este cliente é considerado mais complexo.

[...] a unidade coronariana é uma unidade de pacientes graves. [...] a diferença é que os que estão necessitando de mais tecnologia geralmente são pacientes mais graves [...] e o paciente que não está usando tecnologia, normalmente é um paciente que está um pouco menos grave (EVFD4).

Esta unidade de registro reforça a idéia da relação estreita entre tecnologia e gravidade do cliente, pois a depoente utiliza-se da tecnologia para estabelecer a diferença entre quem está mais ou menos grave. Ao utilizar-se do referencial da tecnologia para avaliar o cliente como mais ou menos grave, a enfermeira pode estar negligenciando a atenção para os clientes que eles consideram menos grave e, aí, não identificar sinais e sintomas destes clientes que demandam cuidados.

As RSs se referem à forma como os sujeitos apreendem os fenômenos da vida cotidiana, as informações circulantes, os objetos presentes no ambiente, no intuito de dominá-lo, compreender e explicar os fatos do nosso universo, agir sobre ele, responder às questões que o mundo nos coloca. ${ }^{4}$ Tal conhecimento se fundamenta nas experiências, informações, saberes que são recebidos e transmitidos durante a trajetória de vida. A RS é um conhecimento prático. Forma-se para dar condições aos sujeitos de atuarem e lidarem com os objetos no cotidiano. Na formação das RSs, os sujeitos reúnem conhecimentos prévios, sentidos construídos, mobilizam afetos. Se no ambiente do CTI, na prática, o aparato tecnológico substitui funções, otimiza o funcionamento do organismo, objetiva e torna visível o que é externamente invisível no corpo, e tudo isso é feito quando o paciente está grave, isto explica o porquê de a idéia sobre a tecnologia ocorrer amparada no quesito gravidade do cliente, pois é assim que efetivamente a tecnologia se apresenta na prática.

Esta consideração ganha força quando se pensa no itinerário terapêutico do cliente e se reflete sobre as condições do sistema de saúde. A diminuição da oferta de leitos e o aumento da demanda por atendimento à saúde, evidenciados, sobretudo, pelo aumento da expectativa de vida da população, fazem com que o cliente chegue ao CTI em situações extremas, muitas vezes de difícil resolução, o que faz com neste local ocorram muitas mortes. Neste sentido, as pessoas associam a gama de aparelhos e a necessidade deles às péssimas condições de viabilidade do cliente.

\section{O cuidado tecnológico}

A representação que se constrói da tecnologia associando-a a gravidade do cliente e sua possível morte (proximidade com) implica em uma ação inerente ao cuidado. No entanto, a diferença está no gradiente que, por conta desta representação, superlativa tal ação. Este cuidado, denominado nesta pesquisa como tecnológico, se estabelece como resposta à forma como se manifestam, na prática, os elementos que compõem a noção sobre a tecnologia. Neste sentido, os sujeitos tipificam dois grupos de cuidados: um mais específico, denominado de especial e diferenciado, realizado na dependência da utilização da tecnologia no cliente; e outro, dirigido aos demais clientes.

O cuidado você vai ter em relação a todos os pacientes, mas com relação à tecnologia que você aplica ao doente, que o paciente exige naquele determinado momento, isso leva o enfermeiro a ter um cuidado diferenciado (EVFD8).

Cuidar de um paciente que precisa de tecnologia e cuidar de um que não precisa de alta tecnologia é bastante diferente por conta da presença da tecnologia (EVMD19).

O que marca a diferença entre o cuidado do cliente que precisa de tecnologia daquele que não precisa, é o gradiente de conhecimento que o enfermeiro necessita aplicar para cuidar desses clientes. Para cuidar daquele que depende de tecnologia, é preciso lançar mão de um maior aporte de conhecimentos que o possibilite não somente manusear as aparelhagens relativas ao cuidado, mas também, interpretar as informações fornecidas por estas procurando associá-las aos sinais e sintomas que o cliente apresenta. Tal necessidade resulta do entendimento que se tem do ambiente e do cliente permeado por idéias de complexidade, dificuldade e gravidade.

O que diferencia mesmo é o conhecimento que a gente tenha a respeito da tecnologia que esteja implicada naquele paciente (ENFN14).

[...] por isso que é diferenciado e mais difícil [...] só que em um você tem que incluir mais, um conhecimento mais teórico, diria assim mesmo, uma coisa mais específica do equipamento que é usado em um e em outro não (EVFD6).

As RSs são categorias que servem para classificar as circunstâncias, fenômenos, pessoas com as quais se tem contato, permitindo definir seus status. É, por fim, um instrumento para compreender o outro, nos conduzindo diante dele e lhe atribuindo um lugar social. ${ }^{4}$ Se as RSs ajudam a 
classificar e pôr ordem nas coisas, ajuda a definir as prioridades e as ações. Por isso o gradiente é importante de ser detectado, pois nos ajuda a entender o porquê das ações, qual lógica sustenta as escolhas, por que o cliente que usa a tecnologia precisa de um cuidado diferenciado em relação àquele que não a utiliza.

Ainda no que tange à questão do conhecimento como um dos aspectos que sustentam o discurso da tipologização do cuidado, é importante destacar a necessidade de intermediação de uma série de saberes para cuidar do cliente que depende de tecnologia. Portanto, é fundamental que o enfermeiro detenha conhecimento em relação às máquinas, aos aspectos fisiopatológicos da doença em curso, assim como sobre a semiologia que o possibilite estabelecer as interfaces entre os sinais e sintomas referidos ou apresentados pelos clientes, com as informações provenientes das máquinas e as manifestações clínicas da doença, aliando-os aos elementos fundamentais do cuidado de enfermagem, que incluem o toque, a audição e a observação. Ao reunir tais habilidades ele consegue realizar esse cuidado especial.

Você também tem que ter o conhecimento da patologia, conhecimento prático, conhecimento também da assistência que você está prestando ao paciente e saber também que não é só olhar para o monitor, você também tem que levar em consideração o que o paciente sente. Acho que é isso (EVFD5).

Outra diferença é o nível de atenção exigida. Segundo os enfermeiros, quando o cliente está sob uso de tecnologia, o acompanhamento de sua evolução clínica precisa ser mais acurado. É importante que o enfermeiro esteja a todo o tempo direcionando sua avaliação a estes clientes, no intuito de identificar demandas que requeiram cuidados de enfermagem para serem atendidas, uma vez que o grau de dependência dele também é maior.

O paciente que precisa de tecnologia acho que denota mais atenção, não sei, mais [pausa] não sei [pausa] mais atenção [pausa] mais, um paciente que a gente realmente tem que estar mais atenta (ENFD1).

[...] a diferença é basicamente essa: é o grau de atenção que você tem que dar para um e para outro, porque um paciente com recurso tecnológico você acaba tendo que ficar sua atenção o tempo todo voltada para ele (EVFD4).

O cuidado tecnológico, portanto, é diferenciado, marcado pela aplicação de maior conhecimento pelo enfermeiro, o qual orienta sua atenção em busca de dados objetivos e subjetivos oriundos do cliente, bem como objetivos provenientes do uso do maquinário. Assim, este cuidado tecnológico se efetiva amparado nas representações que os enfermeiros constroem sobre a tecnologia associando-a a gravidade do cliente e a proximidade da morte, o que produz a necessidade de uma prática voltada a reverter este quadro em que há um risco iminente de morte do cliente.

\section{A figura-tipo do profissional}

O perfil do profissional para trabalhar em cenários tecnológicos, onde os clientes estão permanentemente sob dependência das tecnologias, deve responder às demandas referentes ao tipo de sujeito atendido e às características do ambiente, que por sua vez determinam o modo como se configura o cuidado, o qual se caracterizou como tecnológico.

Neste sentido, tal profissional precisa apresentar múltiplas facetas, no intuito de ser capaz de atender às necessidades de atuação requeridas por este tipo de cuidado, que é diferenciado, requer maior aplicação de conhecimento e interlocução com vários saberes. O espaço deste cuidado é marcado por intensa renovação do conhecimento em virtude do avanço tecnológico, o que exige do enfermeiro uma postura pró-ativa, isto é, precisa demonstrar interesse e vontade na busca contínua pelo conhecimento, para que possa ser posteriormente aplicável no cuidado à clientela.

Eu acho que o perfil é justamente esse, ter interesse, buscar, querer ter conhecimento, ter vontade de aprender, ter disponibilidade para se doar ao cuidado daquele tipo de clientela, disponibilidade para conhecer acerca da tecnologia, do maquinário (ENFD1).

O recém formado pode trabalhar, desde que tenha esse nível de compromisso e reconheça em si essa vontade de aprender, de estar somando, de buscar (EVFD8).

É no perfil e na dimensão da ação frente à tecnologia que reside a diferença entre o enfermeiro novato e o veterano, pois como o novato, na maioria das vezes, não domina o instrumental e a linguagem tecnológica, em princípio, ele se afasta do cliente que esteja em uso de muitos aparatos, pois não sabe dialogar com os sinais que emanam das máquinas, o que o impede de cuidar plenamente do cliente. Na dependência do perfil pessoal-profissional, identificaram-se duas atitudes: a do enfermeiro que passa a atuar somente no que é essencial, mantendo certo afastamento do cliente dependente de tecnologia; e a do 
enfermeiro que se lança ao conhecimento através da ajuda de enfermeiros veteranos, ampliando o saber por estratégia informais de aquisição de conhecimentos e, também, através das formais fazendo cursos, estudando os manuais técnicos para vencer as dificuldades cotidianas.

Eu tentei me ligar às pessoas nas quais eu via maior inteiração com a máquina, as pessoas que entendiam a máquina, pedia para elas me explicarem e qualquer dúvida que eu tinha no momento, eu chamava a pessoa para me explicar (ENFD10).

Alguns são bastante interessados, tentam superar isso. Tentam adquirir o conhecimento, a experiência adequada e ao longo dos plantões vão evoluindo. Outros não. Outros parecem que ficam ali, não têm interesse, não se adaptaram e procuram se afastar desses pacientes. Procuram pacientes que dependam menos de tecnologia (EVMD19).

O conhecimento científico se objetiva no cuidado, possibilitando uma interação efetiva com o cliente, uma vez que a experiência e o saber se constituem como formas de se aproximar do outro que precisa de cuidado. Os profissionais devem possuir habilidades para observar os clientes através dessas máquinas e proceder a avaliações diagnósticas. Assim, a partir da conexão do profissional à máquina é possível realizar uma avaliação dos sintomas referidos pelo paciente na sua interface com a máquina. ${ }^{8}$

Para lidar com a instabilidade, imprevisibilidade, complexidade e gravidade, características do cliente e marcas do ambiente de TI (tecnológico), é fundamental que o enfermeiro seja observador, rápido, dinâmico para identificar as alterações e assistir prontamente o cliente numa intercorrência, sendo capaz de desempenhar mais de uma função simultaneamente; precisa ser comunicativo e ter habilidades de relacionamento de modo a interagir com todos os membros da equipe, bem como liderá-la no direcionamento das atividades a serem realizadas.

Eu acho que tem que ser uma pessoa calma, observadora, que esteja observando o que acontece ao redor dela, rápida, dinâmica [pausa]. Que você tem que ser rápido, para poder atuar em uma emergência com maior rapidez (EVFD9).

Tem que ser atenta, porque muitas vezes situações passam despercebidas se você não está olhando, não está entendendo, [...] um som alarmando ou um parâmetro que não está entrando adequadamente. [...] tem que ser dinâmico, porque às vezes as pessoas pedem milhões de coisas ao mesmo tempo, tem que organizar seu pensamento (ENFD11).
Capacidade de se relacionar como equipe [...]. Isso tem que ser uma característica, uma qualidade. [...] as unidades de terapia intensiva são unidades que basicamente reúnem todas as especialidades de saúde. E há necessidade que esse profissional tenha essa facilidade de se relacionar com todos (EVMN13).

Uma pessoa que tivesse liderança, porque você tem um contato muito próximo com uma equipe multidisciplinar. [...] tem que ser uma pessoa que saiba liderar, que seja uma pessoa que saiba interagir com os outros profissionais (ENFD15).

O ambiente do CTI é caracterizado pela instabilidade. Os plantões envolvem um clima de agitação, o que determina a necessidade de atenção e cuidado rigoroso de todos os membros dessa equipe. Neste cenário, há dias tranqüilos como também dias agitados em que há clientes graves, tornando este ambiente bastante instável. ${ }^{9}$

Para dar conta de um ambiente de cuidado onde a morte sobressai e, consequentemente, produz tensão e estresse nos profissionais, e medo nos clientes, é importante que o enfermeiro seja equilibrado emocionalmente para enfrentar estas situações, conseguir trabalhar e liderar sua equipe. Além disso, é necessário que seja destemido, goste de desafios e esteja disposto a vivenciar novas experiências a cada dia de trabalho, visto que o ambiente é caracterizado pelos depoentes desta pesquisa como difícil, onde as dificuldades aparecem a qualquer momento. Neste sentido, o profissional precisa estar pronto para estas situações que os afrontam e causam estranhamento. Segundo os enfermeiros, para trabalhar no CTI os profissionais tem que reunir algumas características como:

[...] ser uma pessoa equilibrada, não pode desequilibrar em qualquer [pausa] numa parada [cárdiorespiratória], entendeu? (EVFD5);

[...] ser um profissional destemido, estar sempre pronto a novas aventuras, a situações de risco, [...] estar sempre pronto, alerta, não pode ter medo do paciente (EVFD6);

[...] tem que ter um preparo na parte clínica, tem que estudar, mas acima de tudo você tem que ter um suporte emocional muito grande. [...] Esse é o tipo de enfermeira: aquela que queira realmente cuidar, estar mais perto daquele paciente e ter aquele suporte emocional, ter estabilidade emocional (EVFD7).

Uma das características que compõe o perfil do enfermeiro indicado para atuar no CTI, delineado pelos sujeitos entrevistados, é a demonstração do desejo e vontade de estar presente neste ambiente de cuidado, além de gostar de cuidar. 
[...] acho que o principal é você gostar, porque tem gente que não se adapta a trabalhar em setor fechado, [...] tem que gostar mesmo do que está fazendo (EVFD5).

Precisa ter afinidade com este campo especializado do saber, gostar e sentir-se bem com as atividades que desempenha, pois somente a partir deste elemento fundamental que é o atendimento das preferências do profissional, tornar-se-á possível o desenvolvimento de motivação, que se repercutirá em empenho na assistência de enfermagem.

\section{CONCLUSÕES}

Os resultados da pesquisa permitiram que se identificasse os elementos que compõem o campo das RSs sobre a tecnologia própria aos cenários de TI. O campo é onde as RSs se organizam permitindo que se entenda o que pensam e como agem os sujeitos diante do objeto representado. ${ }^{10}$ Do campo das RSs sobre a tecnologia própria à TI fazem parte $\mathrm{o}$ ambiente (que remete à morte), $\mathrm{o}$ cliente (grave, em risco de morte), o cuidado (diferenciado, especial) e o profissional (figura-tipo com características peculiares).

A idéia de que a tecnologia no ambiente da TI é necessária porque o cliente está grave e corre risco de morte iminente perpassa as RSs dos enfermeiros. Disto resulta que a falta de conhecimento acerca dos saberes envolvidos no cuidado e ao manuseio da máquina é determinante para a sua vida ou morte.

No que tange aos dois grupos de sujeitos investigados, não foram identificadas diferenças entre as RSs dos enfermeiros novatos e veteranos, mas foi possível observar que a pouca experiência no cuidado à clientela e no manuseio das máquinas pelos novatos diferenciam suas ações. O não domínio da linguagem tecnológica por vezes impede o novato de se aproximar do cliente para cuidá-lo. Este afastamento ocorre porque o manuseio equivocado das máquinas e/ou a não tradução/interpretação de seus dados podem trazer consequências danosas para o cliente e até levá-lo à morte. A formação profissional prepara o enfermeiro para restabelecer as condições de saúde do cliente e jamais provocar a sua morte, constituindo-se esta situação num tabu, algo difícil de lidar. Daí se explica comportamentos de afastamento do cliente e a dependência de um enfermeiro mais experiente (veterano) para que possa ajudá-lo a cuidar.

Esta dimensão da ação implicada nas RSs da tecnologia, guarda nexos com o gradiente de co- nhecimento requerido para manusear a tecnologia e cuidar do cliente no ambiente do CTI. Novatos e veteranos ressaltaram a importância que o conhecimento técnico e científico sobre o cuidado e sobre as tecnologias adquire neste cenário.

O ambiente do CTI, com suas particularidades em termos de clientela e de tecnologia, requer um enfermeiro com características peculiares que definem a figura-tipo profissional. Desta fazem parte algumas qualidades inerentes à personalidade e estilos próprios de ser dos sujeitos, além de gostar de trabalhar nesse cenário.

A aplicação da TRS como referencial na análise dos dados mostrou que o senso comum que permeia o entendimento do ambiente de CTI vincula-o à morte, medo, gravidade, sofrimento, entre outros, influenciando assim o pensamento/ ação sobre as tecnologias. Nesse sentido, é importante considerar que o enfermeiro, ao chegar neste cenário para atuar, traz consigo as marcas das informações que obteve ao longo da vida, através das conversações cotidianas e, meios de comunicação oficiais, sobre a internação do cliente e o trabalho no CTI.

No caso desta pesquisa, as limitações do método se impõem o que leva a não generalização dos resultados. No entanto, ao entender que o indivíduo articula as informações prévias que circulam no imaginário sobre a tecnologia e o CTI aos seus afetos, e que sua ação muito se deve ao conhecimento que a partir daí é gerado, deve-se pensar em estratégias que oportunizem aos enfermeiros a (re)interpretação da realidade, além de políticas de alocação de pessoal que privilegiem as especialidades e as preferências dos enfermeiros pelos espaços de cuidado para atuarem.

\section{REFERÊNCIAS}

1. Andrade LFS. A complexidade do cuidado de Enfermagem no CETIP/HSE e a necessidade da formação especializada dos enfermeiros [dissertação]. Rio de Janeiro (RJ): Universidade Federal do Rio de Janeiro. Programa de Pósgraduação em Enfermagem; 1999.

2. Benner P. From novice to Expert: Excellent and Power in Clinical Nursing Practice. California (US): Addison Wesley; 1984.

3. Barbosa SFF. A transcendência do Emaranhado Tecnológico em Cuidados Intensivos: a (re)invenção possível. Blumenau (SC): Nova Letra; 1999.

4. Jodelet D. Representações Sociais: um domínio em expansão. In: Jodelet D, organizador. As Representações Sociais. Rio de Janeiro (RJ): EdUERJ; 2001. p.17-44. 
5. Bardin L. Análise de conteúdo. Lisboa (PT): Edições 70; 1979.

6. Lemos RCA, Rossi LA. O significado cultural atribuído ao centro de terapia intensiva por clientes e familiares: um elo entre a beira do abismo e a liberdade. Rev Latino-am Enferm [online]. 2002 Mai-Jun [acesso 2008 Jun 13]; 10(3):345-57. Disponível em: http://www.scielo. br/scielo.php?script=sci_arttext\&pid=S010411692002000300009\&1ng=pt

7. Pinho LB, Santos SMA. Dialética do cuidado humanizado na UTI: contradições entre o discurso e a prática profissional do enfermeiro. Rev Esc Enferm USP. 2008 Jan-Mar; 42(1):66-72.
8. Vargas MAO, Ramos FRS. Tecnobiomedicina: implicações naquilo e daquilo que a enfermagem faz em terapia intensiva. Texto Contexto Enferm [online]. 2008 Jan-Mar [acesso 2008 Jun 13]; 17(1):168-76. Disponível em: http://www.scielo. br/scielo.php?script=sci_arttext\&pid=S010407072008000100019\&lng=pt

9. Leite MA, Vila VSC. Dificuldades vivenciadas pela equipe multiprofissional na unidade de terapia intensiva. Rev Latino-am Enferm [online]. 2005 MarAbr [acesso 2008 Jun 13]; 13(2):145-50 Disponível em: http://www.scielo.br/scielo.php?script=sci_ arttext\&pid=S0104-11692005000200003\&lng=pt

10. Moscovici S. Representações sociais: investigações em psicologia social. Petrópolis (RJ): Vozes; 2003. 